\title{
Modeling the habitat range of phototrophs in Yellowstone National Park: toward the development of a comprehensive fitness landscape
}

\author{
Eric S. Boyd ${ }^{1}{ }^{*}$, Kristopher M. Fecteau ${ }^{2}$, Jeff R. Havig ${ }^{3}$, Everett L. Shock ${ }^{2,3}$ and John W. Peters ${ }^{1}$ \\ ${ }^{1}$ Department of Chemistry and Biochemistry, Astrobiology Biogeocatalysis Research Center, Montana State University, Bozeman, MT, USA \\ 2 Department of Chemistry and Biochemistry, Arizona State University, Tempe, AZ, USA \\ ${ }^{3}$ School of Earth and Space Exploration, Arizona State University, Tempe, AZ, USA
}

\section{Edited by:}

Martha Gledhill, University of Southampton, UK

Reviewed by:

Alan Angelo DiSpirito, lowa State University, USA

James F. Holden, University of Massachusetts Amherst, USA

*Correspondence:

Eric S. Boyd, Department of Chemistry and Biochemistry, Astrobiology Biogeocatalysis

Research Center, Montana State University, 103 Chemistry Research Building, Bozeman, MT 59717, USA. e-mail: eboyd@montana.edu
The extent to which geochemical variation shapes the distribution of phototrophic metabolisms was modeled based on 439 observations in geothermal springs in Yellowstone National Park (YNP), Wyoming. Generalized additive models (GAMs) were developed to predict the distribution of phototrophic metabolism as a function of spring temperature, $\mathrm{pH}$, and total sulfide. GAMs comprised of temperature explained $38.8 \%$ of the variation in the distribution of phototrophic metabolism, whereas GAMs comprised of sulfide and $\mathrm{pH}$ explained 19.6 and $11.2 \%$ of the variation, respectively. These results suggest that of the measured variables, temperature is the primary constraint on the distribution of phototrophs in YNP. GAMs comprised of multiple variables explained a larger percentage of the variation in the distribution of phototrophic metabolism, indicating additive interactions among variables. A GAM that combined temperature and sulfide explained the greatest variation in the dataset $(53.4 \%)$ while minimizing the introduction of degrees of freedom. In an effort to verify the extent to which phototroph distribution reflects constraints on activity, we examined the influence of sulfide and temperature on dissolved inorganic carbon (DIC) uptake rates under both light and dark conditions. Light-driven DIC uptake decreased systematically with increasing concentrations of sulfide in acidic, algal-dominated systems, but was unaffected in alkaline, cyanobacterial-dominated systems. In both alkaline and acidic systems, light-driven DIC uptake was suppressed in cultures incubated at temperatures $10^{\circ} \mathrm{C}$ greater than their in situ temperature. Collectively, these quantitative results indicate that apart from light availability, the habitat range of phototrophs in YNP springs is defined largely by constraints imposed firstly by temperature and secondly by sulfide on the activity of these populations that inhabit the edges of the habitat range. These findings are consistent with the predictions from GAMs and provide a quantitative framework from which to translate distributional patterns into fitness landscapes for use in interpreting the environmental constraints that have shaped the evolution of this process through Earth history.

Keywords: photosynthesis, sulfide, temperature, fitness landscape, $\mathrm{CO}_{2}$ uptake and fixation, habitat range, landscape ecology, distribution

\section{INTRODUCTION}

The distribution of organisms and the functions that they catalyze on Earth today is rooted, at least in part, to the numerous adaptations that enable life to radiate into new ecological niches that have played out over evolutionary time. Such responses are recorded in extant organismal distribution patterns (e.g., habitat range), as well as in the genetic record of organisms. This is a consequence of the predisposition for microorganisms to acquire their ecological traits through vertical inheritance, a phenomenon that manifests in a positive relationship between the ecological relatedness of organisms and their evolutionary relatedness (niche conservatism; Wiens, 2004; Wiens and Graham, 2005). Thus, extant patterns in the distribution of species or metabolic function offer "a window into the past" and can be used to infer historical constraints on the evolution of a particular metabolic function as imposed by the environment (Wiens and Graham, 2005; Westoby, 2006; Boyd et al., 2010; Hamilton et al., 2011a,b). Such observations can in turn be used to predict the response of populations or metabolic guilds to changing environmental conditions (Keddy, 1992; Lavorel and Garnier, 2002; Guisan and Thuiller, 2005).

The extreme variation in the geochemical composition of present day environments is likely to encompass those that were present on early Earth (Shock and Holland, 2007), when key metabolic processes such as photosynthesis are thought to have evolved. Yellowstone National Park (YNP), Wyoming harbors $>12,000$ geothermal features that vary widely in temperature and geochemical composition, both spatially and temporally (Nordstrom et al., 
2005; Shock et al., 2010). Such environments provide a field laboratory for examining the tendency for guilds of organisms to inhabit particular ecological niches and to define the range of geochemical conditions tolerated by that functional guild (i.e., habitat range or zone of habitability; Hoehler, 2007; Shock and Holland, 2007). We assume that since it is unlikely that a metabolic process emerged under environmental conditions that no longer support that function, such information can help quantify the habitat range for a metabolic process, and can provide insight into the characteristics of an environment that enabled the adaptation of that process into new habitats.

Phototrophy is the utilization of solar energy by plants, algae, and certain bacteria to generate energy for the synthesis of complex organic molecules (Blankenship, 1992; Chew and Bryant, 2007). A number of recent studies have documented non-random pattern in the distribution of phototrophic assemblages along geochemical gradients in YNP, Wyoming (Boyd et al., 2010; Cox et al., 2011; Hamilton et al., 2011b). These studies qualitatively identified three ecological axes (temperature, $\mathrm{pH}$, and total sulfide) that appear to constrain the habitat range of phototrophs in the geothermal features of YNP. However, the extent to which each environmental parameter, or combinations therein, shape the distribution of phototrophic metabolism in YNP is unclear. Moreover, it is unclear if the qualitative trends in the distribution of phototrophic metabolism in YNP noted previously are the result of the negative effects that temperature, $\mathrm{pH}$, and sulfide have on the activity of phototrophic populations, which in turn would be expected to decrease fitness and limit their distribution.

Here, in an effort to better define the basis for the observed habitat range of phototrophs in YNP, we compiled environmental metadata and presence/absence distributional data from severalindependent examinations of phototrophic metabolisms across the YNP geothermal complex (Boyd et al., 2010; Cox et al., 2011; Hamilton et al., 2011b). This binary dataset comprising 439-independent observations was used to construct generalized additive models (GAMs) for use in quantifying and ranking the role of temperature, $\mathrm{pH}$, and total sulfide in shaping the habitat range of phototrophs. Using this approach, it was determined that temperature was the primary predictor of the distribution of phototrophs in YNP springs, followed by dissolved sulfide concentration and $\mathrm{pH}$. We evaluated these predictions using short incubation $(<1 \mathrm{~h})$ microcosm studies in several select geothermal springs. Collectively, the GAMs and microcosm studies support a model whereby a temperature of $73^{\circ} \mathrm{C}$ sets the upper temperature limit for phototrophic metabolism in circum neutral to alkaline springs due to constraints imposed by these parameters on the fitness of the constituent populations. The upper temperature limit for the distribution of phototrophic metabolism decreases with decreasing $\mathrm{pH}$ due to the sulfide-dependent suppression of phototrophic activity in algae, the predominant phototrophs in springs with $\mathrm{pH}<5.0$. These results establish the ecological constraints on the activity and presumably the fitness of phototrophs at the edge of their habitat range in YNP and provide insight into the environmental parameters that have shaped the evolution of this key metabolic process over evolutionary time.

\section{MATERIALS AND METHODS PREDICTIVE MODELING}

The binary distribution (presence/absence) of genes involved in chlorophyll biosynthesis and/or phototrophic pigments in a number of geothermal springs sampled from across YNP (Figure 1) and the associated total sulfide, $\mathrm{pH}$, and temperature of the spring water was extracted from three previous studies (Boyd et al., 2010; Cox et al., 2011; Hamilton et al., 2011b). The dataset extracted from Cox et al. (2011) was based on the visual distribution of pigments in geothermal springs, whereas the datasets extracted from Boyd et al. (2010) and Hamilton et al. (2011b) was based on the presence/absence of the protochlorophyllide reductase subunit L gene $(c h l L / b c h L)$ required to synthesize chlorophyll in both anoxygenic and oxygenic phototrophs (Chew and Bryant, 2007) in biomass sampled from geothermal springs in YNP. While the data extracted from each of the aforementioned studies were from observations made in different springs from different regions during different years, plots of the overall phototroph distribution trends with respect to $\mathrm{pH}$, temperature, and sulfide as presented in all three manuscripts (Boyd et al., 2010; Cox et al., 2011; Hamilton et al., 2011b) and in Figures 2A,B revealed the same trends, with an upper temperature limit for photosynthesis of $\sim 73^{\circ} \mathrm{C}$ and a $\mathrm{pH}$-dependent suppression of the upper temperature limit below $\mathrm{pH} \sim 6$. Moreover, the distribution of phototrophic metabolism was constrained to environments with sulfide at a concentration of $<5 \mu \mathrm{M}$ (Cox et al., 2011; Hamilton et al., 2011b). Together, these observations indicate that both methods, as described above, were suitable for mapping the habitat range of phototrophic metabolism along ecological gradients in YNP. By combining the datasets, we were able to sample a much greater portion of the YNP geothermal complex that comprised more than 439 observations, than any one dataset provided alone.

Binomial GAMs describing the distribution of phototrophic pigments and genes involved in their synthesis as proxies for phototrophs were generated using the mgcv package (Wood, 2011) within the base package $\mathrm{R}$ (ver. 2.10.1), using default settings. GAMs are flexible models for fitting smooth curves to data, while maintaining parsimony. In essence, GAMs function to blend the properties of generalized linear models with the features of additive models. These approaches are commonly utilized in describing the distribution of plant species as a function of ecological parameters (Yee and Mitchell, 1991; Guisan et al., 2002). Here, a dependent variable (e.g., distribution of phototrophs) is plotted as a function of an independent variable(s) (e.g., temperature, $\mathrm{pH}$, and sulfide) followed by the calculation of a smooth curve that goes through the data. The GAM approach is considered to be superior to linearbased regression methods (e.g., Pearson correlation analysis) since it does not require the problematic steps of a priori estimation of response curve shape or a specific parametric response function (Hastie and Tibshirini, 1986; Wood, 2004, 2011), but rather allows the data to determine the shape of the response curve in order to maximize the expected log likelihood, or fit of the model to the data. In the present study, GAMs were generated to describe the dependence of the distribution of phototrophic metabolism on environment, specifically spring temperature, $\mathrm{pH}$, and dissolved sulfide concentration. We evaluated the fit of each GAM to the 
data using a number of approaches including the Akaike Information Criterion (AIC), a maximum likelihood-based approach.

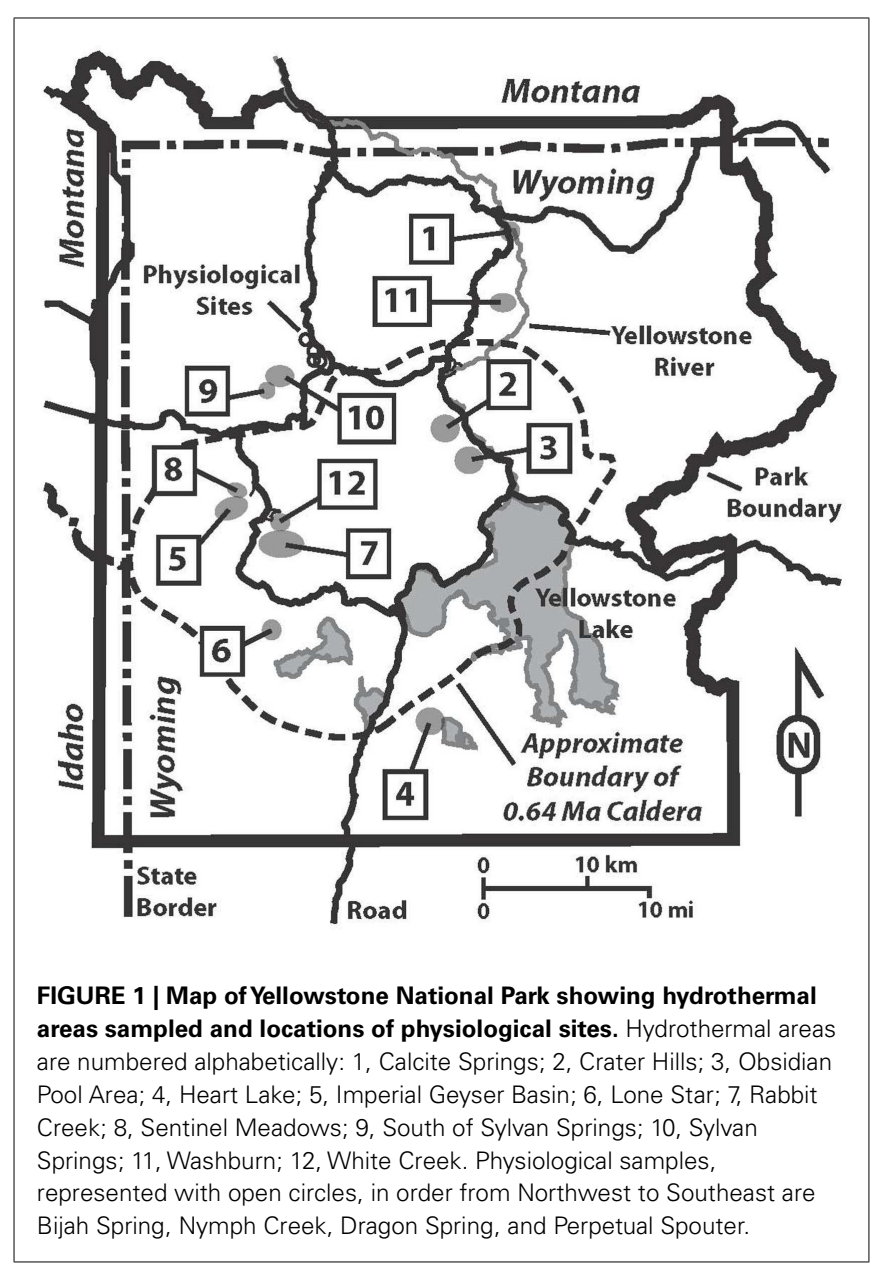

We considered the model with the lowest AIC value to be the best and evaluated the relative plausibility of each other model by examining differences between the AIC value for the best model and values for every other model ( $\triangle \mathrm{AIC}$; Johnson and Omland, 2004). The degrees of freedom (Df) for each model was used as a proxy to estimate the complexity of the model, with more complex models comprised of more Df. Models that achieve minimal AIC and residual deviance on the fewest Df (introduction of few smooth parameters during data fitting) are more likely to replicate in subsequent validation studies, when compared to those with greater Df (introduction of the additional smooth parameters during data fitting). Thus models with low AIC and low Df are lower complexity and are more parsimonious with the data.

\section{GEOCHEMICAL ANALYSES}

$\mathrm{pH}$ and temperature were measured with a WTW 330i meter and probe (WTW Inc., College Station, TX, USA) or a model 59002-00 Cole-Parmer temperature-compensated $\mathrm{pH}$ meter (Vernon Hills, IL, USA). Conductivity was measured with a model YSI30 or YSI EcoSense EC300 conductivity meter (YSI, Yellow Springs, OH, USA). Total dissolved sulfide was determined using the methylene blue method and a Hach DR/2000 spectrophotometer (Hach Company, Loveland, CO, USA). Aliquots used for analysis of dissolved inorganic carbon (DIC) were collected in $40 \mathrm{~mL}$ amber borosilicate vials with black butyl septa. All sample vials were filled to minimize head space and sealed to minimize degassing and atmospheric contamination. DIC concentrations were measured with an OI Analytical Model 1010 Wet Oxidation TOC Analyzer. DIC determinations for Perpetual Spouter and Dragon Spring, both of which were performed in August of 2011, were determined using an ON-LINE TOC-VCSHTOC/TIC and TN analyzer (Shimadzu Scientific Instruments, Columbia, MD, USA). Biofilms/sediments were dried in an oven for 3 days at $\sim 90^{\circ} \mathrm{C}$, and ground with an agate mortar and pestle until uniformly powdered.

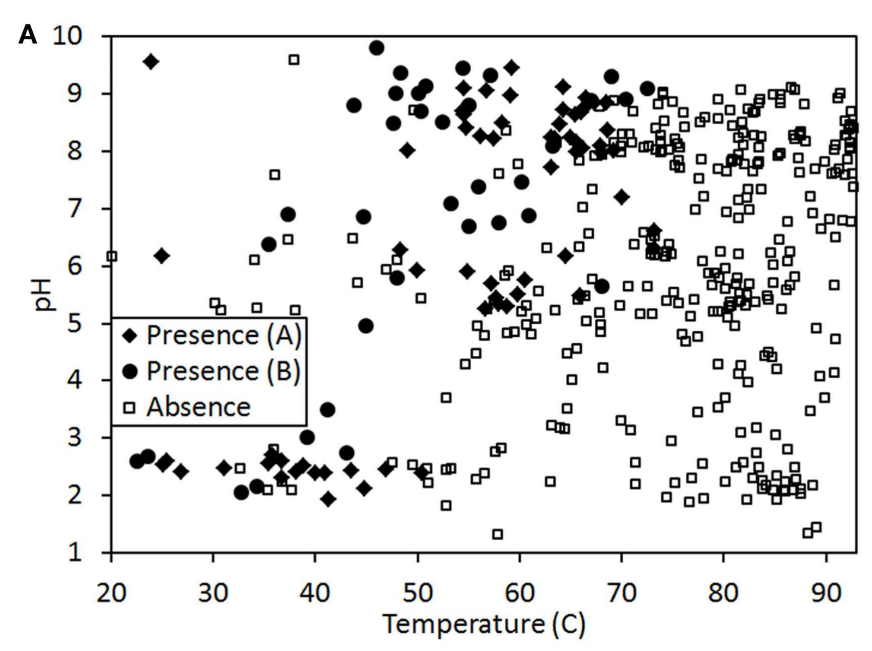

FIGURE 2 | Presence $(\diamond$, for samples assessed via visual inspection for pigments; $\boldsymbol{O}$, for samples assessed via genetic technique; see Materials and Methods for further description) and absence $(\square)$ of phototrophic pigments and/or genes

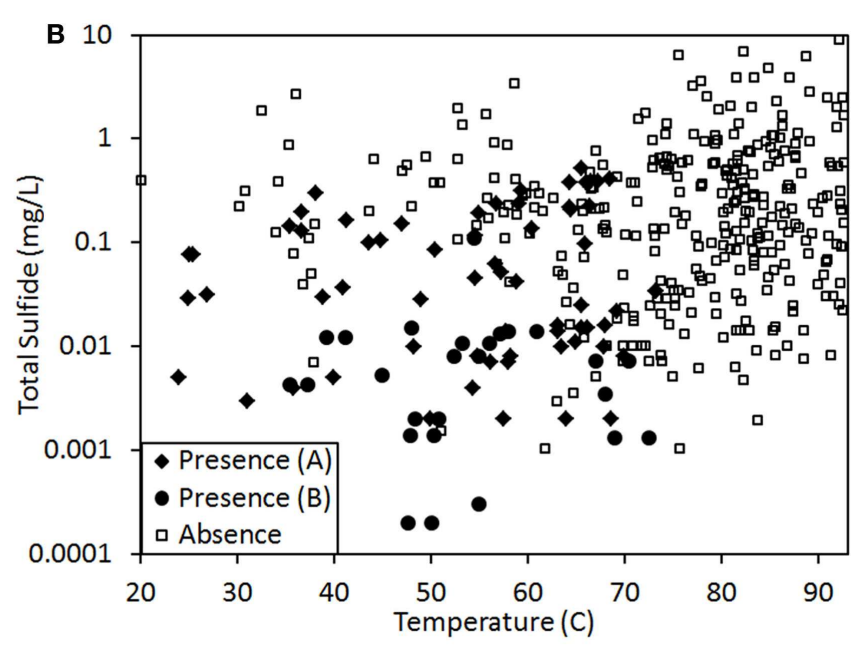

involved in their synthesis in $\mathbf{4 3 9}$ geothermal springs in YNP plotted as a function of spring temperature and $\mathrm{pH}(\mathrm{A})$ or spring temperature and total sulfide concentration (B). Total sulfide concentration is plotted on a log plot. 
Samples were weighed and placed into tin cups, sealed, and analyzed via Costech Model ECS 4010 Elemental Analyzer (Costech Analytical Technologies Inc., Valencia, CA, USA) attached to a Thermo Delta ${ }^{\text {plus }}$ Advantage Isotope Ratio Mass Spectrometer (EA-IR-MS; Thermo Fisher Scientific Inc., Waltham, MA, USA). Data were standardized using the organic standards described above, and linearity was checked using NIST SRM 2710 (Montana Soil).

\section{INORGANIC CARBON UPTAKE IN CHEMOTROPHIC AND PHOTOTROPHIC COMMUNITIES}

Total DIC uptake was assessed using slight modifications to methods described previously (Boyd et al., 2009b). Briefly, chemotrophic and phototrophic mats were collected from points that were approximately $1 \mathrm{~cm}$ up gradient (chemotrophic mat) and $1 \mathrm{~cm}$ down gradient (chlorophototrophic mat) from the photosynthetic fringe at Bijah Spring (Norris-Mammoth Corridor; Easting: 521287, Northing: 4956460), Nymph Creek (Norris Geyser Basin; Easting: 521690, Northing: 4955601), and Dragon Spring (Norris Geyser Basin; Easting: 522889, Northing: 4953218; Figure 1) during March of 2010 (Table 1). The sampling locations in each spring were perpendicular to the photosynthetic fringe. Samples were collected aseptically using a syringe and were placed in a $15 \mathrm{~mL}$ sterile polypropylene tube, with the exception of the chemotrophic community at Bijah Spring (see below). The tube and the contents were shaken vigorously to uniformly resuspend the contents and create a slurry. From this slurry, $500 \mu \mathrm{L}$ aliquots of re-suspended solids were injected into pre-sterilized and anaerobic ( $\mathrm{N}_{2}$ headspace) $20 \mathrm{~mL}$ serum bottles sealed with a butyl stopper. Alternatively, in the case of chemotrophic communities from Bijah Spring, $\sim 500 \mathrm{mg}$ of sediment was placed in $20 \mathrm{~mL}$ serum bottles using a sterile scoop. Bottles containing Bijah Spring chemotrophic sediments were then capped, sealed, and purged with $\mathrm{N}_{2}$ gas. In all experiments, $10 \mathrm{~mL}$ of spring water sampled directly at the photosynthetic fringe was injected into each vial such that the spring water and gas composition was the same. Killed controls were prepared by addition of glutaraldehyde to a final concentration of $2.0 \%, \mathrm{v} / \mathrm{v}$. To assess the potential for dark DIC uptake, vials were wrapped completely in aluminum foil. All assays (biological and killed controls, light and dark incubations) were performed in triplicate. The reaction was initiated by addition of $\mathrm{NaH}_{14} \mathrm{CO}_{3}$ (MP Biomedicals, $422 \mathrm{MBq} / \mathrm{mmol}$ ) to a final concentration of $2.13 \times 10^{6} \mathrm{~Bq} / \mathrm{L}$. Serum bottles were placed in a clear polypropylene bag (secondary containment) and were incubated in the spring at the photosynthetic fringe for approximately $60 \mathrm{~min}$. Following incubation, vials were placed directly on dry ice to stop the reaction. The vials remained frozen until further processed at the lab. Vials were thawed and acidified to $\mathrm{pH}<2.0$ using concentrated $\mathrm{HCl}$. Serum bottles and their contents were degassed with $\mathrm{N}_{2}(\sim 5 \mathrm{~min}$.) and the biomass was filtered onto $0.2 \mu \mathrm{m}$ pore size, $25 \mathrm{~mm}$ diameter white Nucleopore polycarbonate membranes (Whatman Inc., Florham Park, NJ, USA). Filtered biomass was washed with $\sim 10 \mathrm{~mL}$ of sterile denionized water, placed in scintillation vials, and dried at $80^{\circ} \mathrm{C}$ overnight. In the case of samples from Bijah Spring, the vials containing sediment were then weighed and subtracted from empty vials such that all measurements could be normalized to grams of organic nitrogen present in the inoculum. The total solid content in each slurry used to inoculate the reactions (with the exception of Bijah chemotrophic communities) was determined by drying triplicate $1 \mathrm{~mL}$ aliquots at $80^{\circ} \mathrm{C}$ for $48 \mathrm{~h}$.

Dried biomass and filters were overlain with $10 \mathrm{~mL}$ Cytoscint and were subjected to liquid scintillation counting as previously described (Boyd et al., 2009b). Total uptake was determined using previously described methods (Lizotte et al., 1996) using DIC numbers determined for each spring. For the purpose of comparing total DIC uptake between chemotrophic and phototrophic communities, rates of uptake were first normalized to dry weight of biomass per reaction and then to grams of organic nitrogen. All reported values reflect the difference in uptake between biological controls and glutaraldehyde-killed controls.

\section{INFLUENCE OF SULFIDE AND TEMPERATURE ON DIC UPTAKE IN PHOTOTROPHIC COMMUNITIES}

The influence of sulfide on DIC uptake in phototrophic communities was determined using the same approach as described above. Experiments were performed at Nymph Creek (May 2010),

Table 1 | Physical and chemical measurements made at sampling sites.

\begin{tabular}{|c|c|c|c|c|c|c|c|c|}
\hline Source & Sampling date & Biofilm type ${ }^{a}$ & Temperature $\left({ }^{\circ} \mathrm{C}\right)$ & $\mathbf{p H}$ & DIC (ppm C) & DOC (ppm C) & $w t \% C^{b}$ & $\mathbf{w t} \% \mathbf{N}^{\mathbf{b}}$ \\
\hline \multirow[t]{2}{*}{ Dragon Spring } & 3/13/2010 & Chemo & 58.0 & 3.13 & 5.9 & 0.91 & 1.08 & 0.13 \\
\hline & $3 / 13 / 2010$ & Photo & 46.5 & 2.95 & 0.6 & 0.90 & 0.95 & 0.44 \\
\hline \multirow[t]{2}{*}{ Nymph Creek } & $3 / 14 / 2010$ & Chemo & 56.8 & 2.99 & 10.5 & 0.60 & 11.71 & 2.85 \\
\hline & $3 / 14 / 2010$ & Photo & 53.0 & 3.00 & 26.4 & 0.53 & 11.45 & 2.01 \\
\hline \multirow[t]{2}{*}{ Bijah Spring } & $3 / 14 / 2010$ & Chemo & 72.5 & 7.52 & 57.8 & 0.78 & 0.19 & 0.02 \\
\hline & $3 / 14 / 2010$ & Photo & 68.8 & 7.65 & 60.2 & 0.68 & 0.70 & 0.09 \\
\hline Perpetual Spouter & 8/18/2011 & Photo & 68.6 & 7.12 & 4.4 & NA & 2.91 & 0.46 \\
\hline Dragon Spring & 8/18/2011 & Photo & 46.2 & 2.60 & 14.4 & NA & 7.67 & 1.36 \\
\hline
\end{tabular}

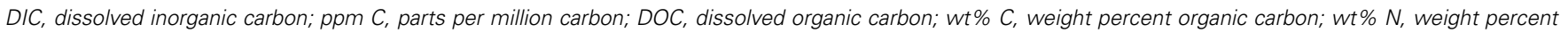
organic N; NA, not available.

aThe type of biofilm as classified as either chemotrophic (Chemo) or phototrophic (Photo).

${ }^{b}$ Weight percent organic carbon and organic nitrogen of bulk biofilms. 
Dragon Spring (August 2011), and Perpetual Spouter (August 2011; Table 1). Perpetual Spouter (Norris Geyser Basin; Easting: 523034, Northing: 4952620) was chosen to replace Bijah Spring, due to difficulties in accessing the latter during periods of heavy visitor traffic. Prior to the initiation of the reaction with $\mathrm{NaH}_{14} \mathrm{CO}_{3}$, microcosms were amended with varying concentrations of an anaerobic and sterile sodium sulfide solution. $\mathrm{Na}_{2} \mathrm{~S}$ was added to microcosms from Nymph Creek at a concentration of 5 and $20 \mu \mathrm{M}$, whereas $\mathrm{Na}_{2} \mathrm{~S}$ amendments of only $5 \mu \mathrm{M}$ were made in microcosms from Perpetual Spouter and Dragon Spring. The concentration of sulfide to amend each microcosm with was determined empirically, such that the final concentration was $\sim 5 \mu \mathrm{M}$ greater than that present naturally at the photosynthetic fringe. Light-independent and killed controls were prepared as described above. All assays (biological and killed controls, light and dark incubations) were performed in triplicate. Reactions were initiated by addition of $\mathrm{NaH}_{14} \mathrm{CO}_{3}$ (MP Biomedicals, $422 \mathrm{MBq} / \mathrm{mmol}$ ) to a final concentration of $1.66 \times 10^{7} \mathrm{~Bq} / \mathrm{L}$. Serum bottles were incubated and processed as described above. The influence of elevated temperature on DIC uptake was examined in phototrophic communities sampled from Perpetual Spouter and Dragon Spring in August of 2011. Microcosms were set up as described above using biomass and spring water sampled from phototrophic mats near the fringe of each respective spring. Light-independent and killed controls were prepared as described above. All assays (biological and killed controls, light and dark incubations) were performed in triplicate. Reactions were initiated by addition of $\mathrm{NaH}_{14} \mathrm{CO}_{3}$ (MP Biomedicals, $422 \mathrm{MBq} / \mathrm{mmol}$ ) to a final concentration of $1.66 \times 10^{7} \mathrm{~Bq} / \mathrm{L}$. Serum bottles were incubated and processed as described above.

\section{RESULTS}

The presence or absence of phototrophic pigments and/or genes involved in their synthesis were used as proxies for examining the distribution of this metabolism along gradients in temperature, $\mathrm{pH}$, and total sulfide in 439 samples (Figure 2) from a variety of geothermal springs throughout YNP (Figure 1) using GAM approaches. GAMs identified spring temperature as the top individual variable for predicting the distribution of phototrophic metabolisms $(\triangle \mathrm{AIC}=92.4, \mathrm{Df}=6.2)$, followed by total sulfide concentration $(\triangle \mathrm{AIC}=192.1, \mathrm{Df}=3.9)$ and spring $\mathrm{pH}$ $(\triangle \mathrm{AIC}=244.2, \mathrm{Df}=8.6$; Table 2$)$. GAMs that comprised temperature explained $38.8 \%$ of the variance in the distribution of phototrophic metabolisms, whereas GAMs that comprised total sulfide or $\mathrm{pH}$ explained 19.6 and $11.2 \%$ of the variance in the dataset, respectively. GAMs that incorporated more than one environmental variable generally fit the data better and explained a greater amount of the variance than GAMs comprised of individual environmental variables, indicating additive interactions among variables. Importantly, the variation in temperature, $\mathrm{pH}$, and sulfide in YNP springs were not correlated (Pearson $R^{2}<0.06$ for all pairwise regressions), indicating that these variables behave independently in the YNP springs analyzed in this study. A GAM that comprised spring temperature, $\mathrm{pH}$, and total sulfide was the top ranking model $(\triangle \mathrm{AIC}=0.0)$ and explained $66.6 \%$ of the variance in the dataset, the most of any GAM, although this

\begin{tabular}{|c|c|c|c|}
\hline GAM & $\Delta \mathrm{AIC}$ & Df & adj $R^{2}$ \\
\hline Temp $+\mathrm{pH}+$ sulfide & 0.0 & 14.7 & 0.666 \\
\hline Temp + sulfide & 39.3 & 8.2 & 0.534 \\
\hline Temp $+\mathrm{pH}$ & 51.3 & 11.1 & 0.529 \\
\hline Temp & 92.4 & 6.2 & 0.388 \\
\hline $\mathrm{pH}+$ sulfide & 151.6 & 9.7 & 0.289 \\
\hline Sulfide & 192.1 & 3.9 & 0.196 \\
\hline $\mathrm{pH}$ & 244.2 & 8.6 & 0.112 \\
\hline
\end{tabular}

GAM, generalized additive model; Df, degrees of freedom; adj $R^{2}$, sample size adjusted $R^{2}$ or the fraction percent of variance explained.

model required the introduction of 14.7 Df. GAMs that comprised temperature and sulfide $(\triangle \mathrm{AIC}=39.3)$ and temperature and $\mathrm{pH}(\triangle \mathrm{AIC}=51.3)$ explained lower fractions of the variance in the dataset (53.4 and $52.9 \%$, respectively), but required the introduction of fewer Df (8.2 and 11.1, respectively). Collectively, the GAM that comprised temperature and sulfide explained the greatest amount of the variation in the dataset while minimizing the introduction of Df.

Prior to examining the influence of physical and chemical constraints on the activity of phototrophs in YNP, it was necessary to determine if the photosynthetic fringe (Figure 3) was the result of competition between phototrophs and chemotrophs for this niche, as this was previously suggested (Boyd et al., 2009b). Competition experiments were performed at the photosynthetic fringe in Nymph Creek ( $\mathrm{pH} 2.99,52.7^{\circ} \mathrm{C}$ ), Dragon Spring ( $\mathrm{pH} 2.95$, $46.5^{\circ} \mathrm{C}$ ), and Bijah Spring $\left(\mathrm{pH} 7.40,70.0^{\circ} \mathrm{C}\right)$ in March of 2010. The phototrophic assemblages near the photosynthetic fringe at both Nymph Creek and Dragon Spring are both comprised of algae related to Cyanidioschyzon sp. (Ferris et al., 2005; Lehr et al., 2007; Boyd et al., 2009a), whereas the phototrophic assemblages near the photosynthetic fringe at Bijah Spring are dominated by Synechococcus sp. and Roseiflexus sp. (King et al., 2006). Populations comprising the chemosynthetic assemblages near the fringe in both Nymph Creek and Dragon Spring are thought to be comprised primarily of organisms affiliated with Hydrogenobacter sp., Desulfurella sp., and Acidimicrobium sp. (Jackson et al., 2001; Ferris et al., 2003), whereas populations associated with chemotrophic assemblages in Bijah Spring are most closely related to Thermotoga sp. (King et al., 2006).

When incubated in the light, DIC uptake rates in chemotrophic assemblages sampled $\sim 1 \mathrm{~cm}$ from the photosynthetic fringe at Nymph Creek, Dragon Spring, and Bijah Spring (Figure 3) were not significantly different $(P=0.32,0.62,0.47$, respectively), from rates when incubated in the dark (Figure 4), which indicates that the mats were unlikely to be using light to drive DIC uptake. In contrast, rates of DIC uptake in photosynthetic assemblages sampled $\sim 1 \mathrm{~cm}$ from the photosynthetic fringe at Nymph Creek, Dragon Spring, and Bijah Spring were significantly different $(P=0.01$, $0.04,0.01$, respectively), when incubated in the light versus when incubated in the dark, indicating that these assemblages were using 


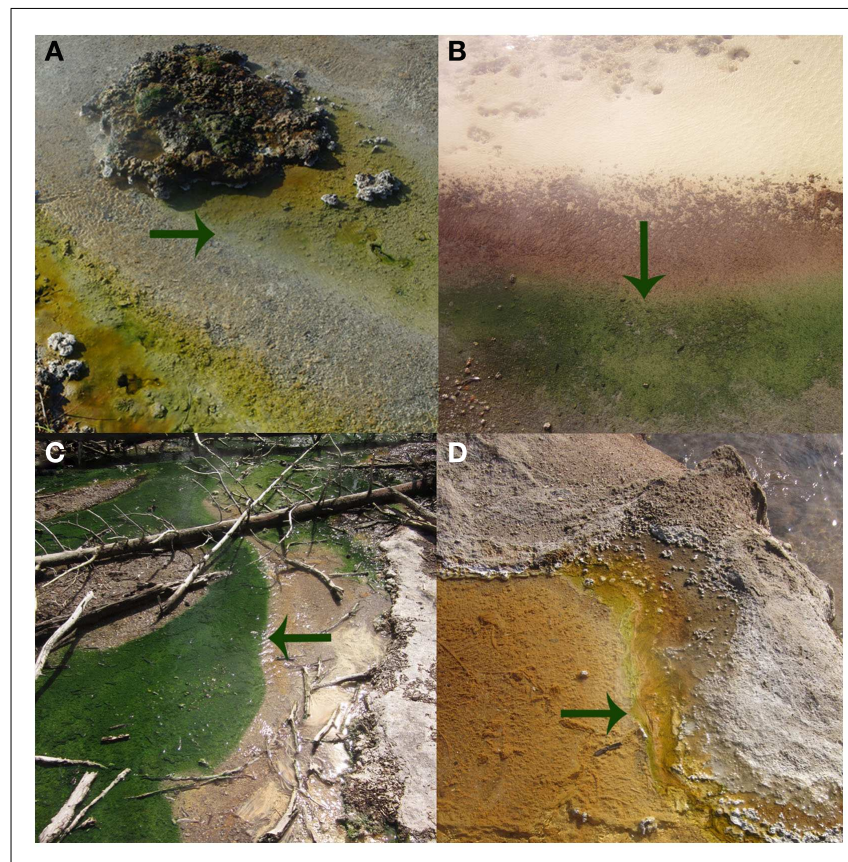

FIGURE 3 |The photosynthetic fringe, or the transition from chemosynthetic to photosynthetic metabolism, as denoted by arrows, for Bijah Spring in March 2010 (A), Dragon Spring in March 2010 (B), Nymph Creek in March 2010 (C), and Perpetual Spouter in August of 2011 (D).

light to drive a portion of DIC uptake. Rates of DIC uptake in phototrophic assemblages sampled $\sim 1 \mathrm{~cm}$ from the photosynthetic fringe at Nymph Creek, Dragon Spring, and Bijah Spring, when incubated in the light, were significantly greater $(P<0.05$ for all comparisons) than rates of DIC uptake in chemosynthetic mats from those springs, regardless of whether the chemosynthetic mats were incubated in the light or the dark. Importantly, rates of DIC uptake in chemotrophic and phototrophic assemblages sampled $\sim 1 \mathrm{~cm}$ on either side of the photosynthetic fringe at Nymph Creek, Dragon Spring, and Bijah Spring, when incubated in the dark, were not significantly different $(P=0.15,0.93$, 0.08 , respectively), suggesting that normalizing overall rates of uptake to organic $\mathrm{N}$ is unlikely to be responsible for the differences in the rates observed in chemotrophic and phototrophic assemblages. Collectively, these results suggest that competition for DIC between phototrophs and chemotrophs is unlikely to be the basis of the photosynthetic fringe observed in acidic (e.g., Nymph Creek and Dragon Spring) and alkaline (e.g., Bijah Spring) ecosystems.

The influence of sulfide on DIC uptake by phototrophic assemblages sampled near the photosynthetic fringe at Nymph Creek (fringe $\mathrm{pH}=2.89$, Temp. $=52.1^{\circ} \mathrm{C}$, total sulfide $\leq 150 \mathrm{nM}$ ), Dragon Spring (fringe $\mathrm{pH}=2.60$, Temp. $=46.2^{\circ} \mathrm{C}$, total sulfide $=\sim 1 \mu \mathrm{M}$ ), and Perpetual Spouter (fringe $\mathrm{pH}=7.12$, Temp. $=68.6^{\circ} \mathrm{C}$, total sulfide $\leq 150 \mathrm{nM}$ ) was examined in both light and dark incubations in March of 2010 (Nymph Creek) and August of 2011 (Dragon Spring and Perpetual Spouter; Figure 3). An amount of sodium sulfide was added to microcosms in order

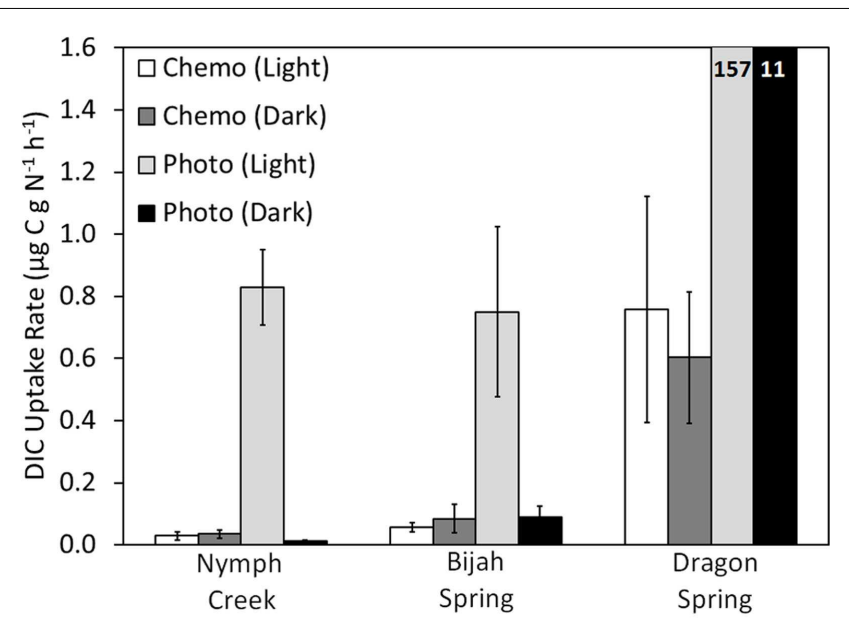

FIGURE 4 | Rate of DIC uptake for chemotrophic and phototrophic assemblages sampled from adjacent sides of the photosynthetic fringe in Nymph Creek (fringe $\mathrm{pH}=2.99$, Temp. $=52.7^{\circ} \mathrm{C}$ ), Bijah Spring (fringe $\mathrm{pH}=7.40$, Temp. $=70.0^{\circ} \mathrm{C}$ ), and Dragon Spring (fringe $\mathrm{pH}=\mathbf{2 . 9 5}$, Temp. $=\mathbf{4 6 . 5} 5^{\circ}$ ). Microcosms were incubated both in the light and the dark and rates reflect the difference between triplicate killed controls and triplicate biological controls, for each treatment. For comparative purposes, DIC uptake rates were normalized to grams organic nitrogen present in the chemotrophic or phototrophic biomass used as inoculum (Table 1). All spring water used in the microcosms was sampled from the photosynthetic fringe and all microcosms were incubated in situ at the photosynthetic fringe temperature. Rates of DIC uptake for the phototrophic assemblages sampled from Dragon Spring are indicated as insets on the histogram.

to generate a final concentration that was $\sim 5 \mu \mathrm{M}$ greater than that present in spring water flowing over the photosynthetic fringe in each spring. When compared to unamended controls, the addition of sulfide to a final concentration of $5 \mu \mathrm{M}$ in microcosms containing photosynthetic mat sampled from near the photosynthetic fringe at Nymph Creek resulted in a significant $(P=0.04)$ decrease ( $\sim 56 \%$ of unamended control rate) in the rate of DIC uptake (Figure 5A). The addition of sulfide to a final concentration of $20 \mu \mathrm{M}$ in microcosms containing photosynthetic mat sampled from near the photosynthetic fringe at Nymph Creek resulted in a significant $(P<0.01)$ decrease $(31 \%$ of unamended control rate) when compared to the unamended control DIC uptake rate (Figure 5A). The DIC uptake rates in unamended controls were not significantly different from the sulfide amended controls (5 and $20 \mu \mathrm{M}$ ) in microcosms containing photosynthetic mat from Nymph Creek when incubated in the dark, suggesting that sulfide did not significantly influence chemosynthetic DIC uptake in the microcosm incubations.

The rate of light-driven DIC uptake was also significantly ( $P=0.04)$ suppressed ( $~ 55 \%$ of unamended control rate) by the addition of sulfide to a final concentration of $5 \mu \mathrm{M}$ in microcosms containing microbial mat sampled near the photosynthetic fringe at Dragon Spring, whereas the rate of dark DIC were not significantly affected $(P=0.33)$ by the addition of sulfide (Figure 5B). Interestingly, the rate of light-driven DIC uptake was not significantly $(P=0.08)$ affected by the addition of sulfide when added to a final concentration of $5 \mu \mathrm{M}$ in microcosms 


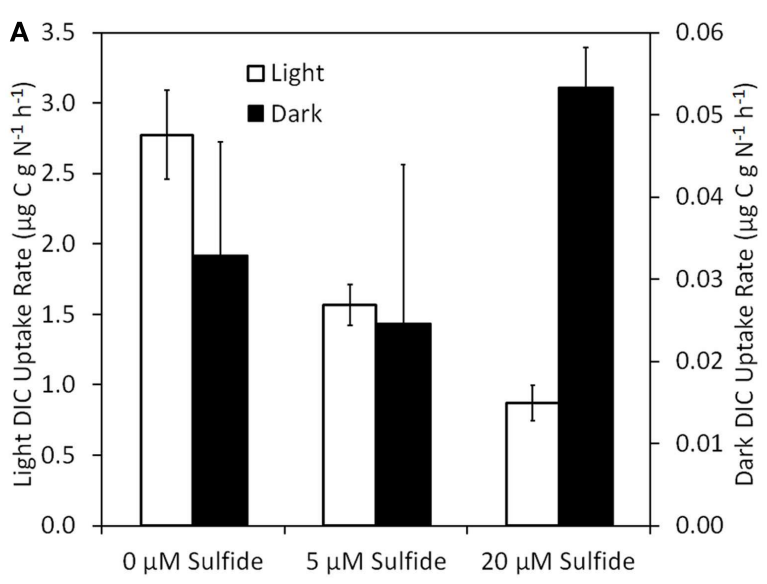

FIGURE 5 | Rate of DIC uptake in phototrophic assemblages sampled from near $(<1 \mathrm{~cm})$ the photosynthetic fringe at Nymph Creek (fringe $\mathrm{pH}=2.89$, Temp. $^{2}=52.1^{\circ} \mathrm{C}$, total sulfide $\leq 150 \mathrm{nM}$ ) as a function of increasing amendment of sodium sulfide to final concentrations of 5 and $20 \mu \mathrm{M}$ when incubated under light and dark conditions (A). Rate of DIC uptake in photosynthetic assemblages sampled from near $(<1 \mathrm{~cm}$ ) the photosynthetic fringe at Dragon Spring (fringe $\mathrm{pH}=2.60$,

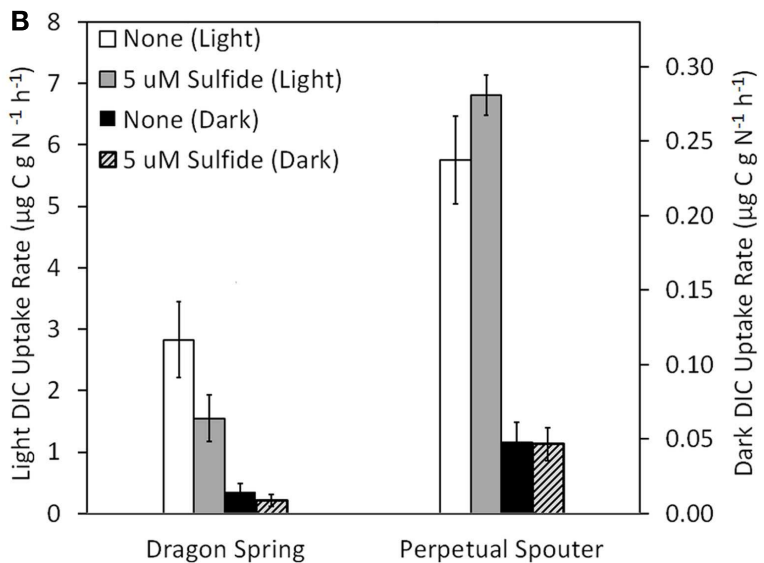

Temp. $=46.2^{\circ} \mathrm{C}$, total sulfide $=\sim 1 \mu \mathrm{M}$ ) and Perpetual Spouter (fringe $\mathrm{pH}=7.12$, Temp. $=68.6^{\circ} \mathrm{C}$, total sulfide $\leq 150 \mathrm{nM}$ ) as a function of amendment of sodium sulfide to final concentrations of $5 \mu \mathrm{M}$ when incubated under light and dark conditions (B). All spring water used in inoculums was sampled from the photosynthetic fringe and rates of DIC uptake were normalized to grams of organic nitrogen present in the biomass used as inoculum (Table 1). containing photosynthetic mat sampled near the photosynthetic fringe at Perpetual Spouter. Likewise, the rate of dark DIC uptake was not significantly $(P=0.93)$ affected by the addition of sulfide when added to a final concentration of $5 \mu \mathrm{M}$ in microcosms containing photosynthetic mat sampled near the photosynthetic fringe at Perpetual Spouter (Figure 5B). Thus, the addition of sulfide suppresses light-driven DIC uptake in the algal-dominated photosynthetic mats present in Nymph Creek and Dragon Spring, but has no significant influence on rates of DIC uptake in Perpetual Spouter, which is dominated by bacterial phototrophs most closely affiliated with Synechococcus sp. and Roseiflexus sp. (Hamilton et al., 2011b). The rate of DIC uptake when incubated in the dark was unaffected by the addition of sulfide, regardless of the sampling location.

The influence of temperature on DIC uptake was examined in phototrophic mats sampled from near the photosynthetic fringe at Dragon Spring (fringe $\mathrm{pH}=2.60$, Temp. $=46.2^{\circ} \mathrm{C}$, total sulfide $=\sim 1 \mu \mathrm{M}$ ) and Perpetual Spouter (fringe $\mathrm{pH}=7.12$, Temp. $=68.6^{\circ} \mathrm{C}$, total sulfide $\leq 150 \mathrm{nM}$ ) in August of 2011. All components of the reaction (inoculum, spring water) were identical in the reactions, with the exception of where in the thermal transect the microcosms were incubated. Incubation of phototrophic mats at a thermal transect $10^{\circ} \mathrm{C}$ greater than that at the photosynthetic fringe resulted in a statistically significant $(P<0.01$ for both Dragon Spring and Perpetual Spouter) decrease in light-driven DIC uptake rates when compared with rates of light-driven DIC uptake in microcosms incubated at the fringe temperature in both Dragon Spring and Perpetual Spouter (Figure 6). The rates of light-driven DIC uptake in microcosms incubated at the higher temperature locations $\left(56\right.$ and $78^{\circ} \mathrm{C}$ for Dragon Spring and Perpetual Spring, respectively), were 3.9 and $2.2 \%$ of the rate of light-driven DIC uptake in microcosms at the fringe temperature of $46^{\circ} \mathrm{C}$ in Dragon Spring and $68^{\circ} \mathrm{C}$ in Perpetual Spouter, respectively (Figure 6). Interestingly, the rate

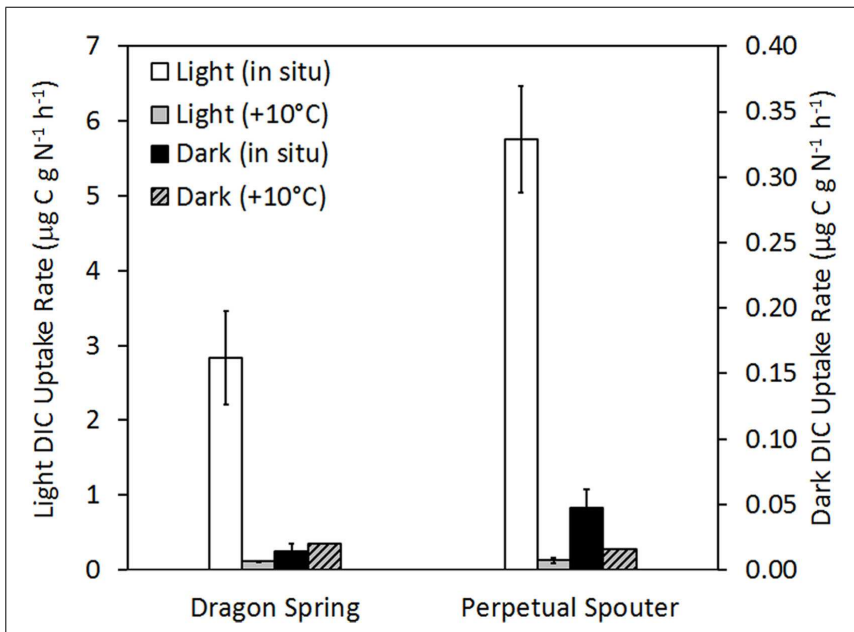

FIGURE 6 | Rate of DIC uptake in phototrophic assemblages sampled from near the photosynthetic fringe at Dragon Spring (fringe $\mathrm{pH}=2.60$, Temp. $=46.2^{\circ} \mathrm{C}$, total sulfide $=\sim 1 \mu \mathrm{M}$ ) and Perpetual Spouter (fringe $\mathrm{pH}=7.12$, Temp. $=68.6^{\circ} \mathrm{C}$, total sulfide $\leq 150 \mathrm{nM}$ ) when incubated the fringe temperature as well as at a temperature $\sim 10^{\circ} \mathrm{C}$ greater than at the fringe temperature $\left(58.0\right.$ and $78.4^{\circ} \mathrm{C}$, respectively), under both light and dark conditions. All spring water used in microcosms was sampled from near the photosynthetic fringe and rates of DIC uptake were normalized to grams organic nitrogen in biomass that served as inoculum (Table 1).

of DIC uptake in microcosms incubated in the dark at the fringe in Dragon Spring was not significantly different $(P=0.17)$ from that measured in microcosms incubated in the dark at the higher temperature locations. In contrast, the rate of DIC uptake in microcosms incubated in the dark at the fringe in Perpetual Spouter was significantly lower $(P=0.04)$ from that measured in microcosms incubated in the dark at the higher temperature locations. 
The rates of DIC uptake in microcosms incubated in the dark at the higher temperature locations in Dragon Spring and Perpetual Spouter were 139 and $32 \%$ of those measured in microcosms incubated at the fringe, respectively. Thus, DIC uptake in algal populations that comprise the phototrophic assemblage at Dragon Spring and the cyanobacterial populations that comprise the phototrophic assemblage at Perpetual Spouter are apparently more sensitive to temperature stress than the chemotrophic populations in these assemblages.

\section{DISCUSSION}

The innovation of photosynthesis, specifically the photosynthetic apparatus capable of splitting water into $\mathrm{O}_{2}$, protons, and electrons, was a pivotal point in the evolution of Earth's biogeochemical cycles (Blankenship, 1992; Anbar, 2008; Falkowski and Isozaki, 2008) and the emergence of complex life (Raymond and Segrè, 2006; Boyd et al., 2011; Wang et al., 2011a). While studies continue to refine our understanding of when these events are likely to have occurred (Anbar et al., 2007; Buick, 2008; Sessions et al., 2009), far fewer studies have focused on understanding the ecological interactions that are likely to have influenced the evolution of photosynthesis. The extreme variation in geochemical composition present in YNP's $>12,000$ geothermal features (Nordstrom et al., 2005; Shock et al., 2010) offer a multitude of spatial gradients that directly select for organisms with enhanced performance or fitness under a given set of conditions (Brock, 1967; Allewalt et al., 2006; Miller et al., 2009). In the present study, the distribution of photosynthesis along spatial gradients of temperature, sulfide, and $\mathrm{pH}$ from 439 geothermal springs was quantitatively mapped using GAMs in order to identify the constraints on the habitat range of phototrophic metabolisms in the YNP geothermal complex. Microcosm studies served to determine whether the edges of the habitat range were due to constraints on the activity of the constituent populations, in an attempt to begin to translate the habitat range to a fitness landscape.

Aside from light availability, GAMs indicated that the primary variable influencing the distribution of photosynthesis was temperature, with sulfide as the second most significant predictor of the distribution of photosynthetic metabolism. These quantitative rankings are consistent with previous qualitative distribution patterns noted across YNP (Cox et al., 2011; Hamilton et al., 2011b) as well as with physiological data obtained from cultivated algae and cyanobacteria. Photosystem II (PSII), the water splitting complex present in cyanobacteria, algae, and plants (Blankenship, 1992, 2010) is sensitive to sulfide in some, but not all, oxygenic phototrophs (Castenholz, 1977; Oren et al., 1979; Miller and Bebout, 2004). To examine whether the sulfidedependent pattern in the distribution of phototrophs is due to suppression of photosynthetic activity (presumably through the toxicity to PSII) DIC uptake rates in the presence and absence of sulfide were compared. DIC uptake in alkaline phototrophic assemblages likely to be dominated by cyanobacteria was unaffected by the addition of $5 \mu \mathrm{M}$ sulfide, whereas DIC uptake in acidic phototrophic assemblages likely to be dominated by algae was suppressed by sulfide at a concentration of $5 \mu \mathrm{M}$. The predominant form of sulfide at acidic $\mathrm{pH}(\mathrm{pH}<6-7)$ is $\mathrm{H}_{2} \mathrm{~S}(\mathrm{aq})$
(Amend and Shock, 2001), which is also the form thought to be responsible for PSII toxicity since it easily diffuses across the cell membrane (Howsley and Pearson, 1979). Thus, the physiological sensitivity to sulfide at concentrations as low as $5 \mu \mathrm{M}$ observed in photosynthetic assemblages inhabiting acidic springs is consistent with the presence of algal phototrophs in acidic environments $(\mathrm{pH}<5.0)$ only when the total sulfide concentration was less than $\sim 5 \mu \mathrm{M}$ (Figure 2). Thus, the physiological constraints imposed by sulfide impairs activity, which in turn likely renders algal populations unfit to successfully replicate in these environments. This decrease in fitness would in turn likely limit the distribution of algae to YNP habitats with sulfide concentrations of $<5 \mu \mathrm{M}$.

Existing data indicate that the photosynthetic populations inhabiting the edge of the phototrophic habitat range in acidic environments $(\mathrm{pH}<5.0)$ are comprised primarily of algae related to Cyanidioschyzon sp. (Ferris et al., 2005; Lehr et al., 2007; Boyd et al., 2009a). The habitat range for Cyanidioschyzon sp. appears to vary depending on the spring being examined. For example, Cyanidioschyzon sp. mats are commonly observed in acidic springs in Norris Geyser Basin and other locales in YNP at temperatures approaching $\sim 57^{\circ} \mathrm{C}$ (Lehr et al., 2007), yet in other acidic springs in YNP and global-distributed hydrothermal fields such as those in Japan, their distribution is constrained to lower temperatures $\left(\sim 40-50^{\circ} \mathrm{C}\right.$; Cox et al., 2011; Hamilton et al., 2011b). This suggests that minor variations in the composition of the fluid in individual acidic springs might be limiting the activity of algal populations and impacting their reproductive fitness and distributional pattern. This hypothesis is consistent with the "patchy" distribution of phototrophic metabolism in environments with $\mathrm{pH}<5$ and temperatures lower than $56^{\circ} \mathrm{C}$ (Figure 2A). Previous studies have noted rapid decreases in sulfide as a function of increasing distances from the source in acidic springs either through degassing or oxidation via biological or abiological mechanisms (Langner et al., 2001; D'Imperio et al., 2008; Cox et al., 2011). This observation, together with the variability in total sulfide concentrations in the source waters of acidic features (Shock et al., 2010), is likely to result in differences among points in the thermal transects where total sulfide concentrations drop below $5 \mu \mathrm{M}$, the apparent upper limit tolerated by Cyanidioschyzon-like populations in YNP (Figure 2B). In turn, such variation would likely impact the temperature at the point in the thermal transect where algal photosynthesis is possible.

The influence of temperature on DIC uptake rates was also examined in alkaline and acidic springs, since a previous study indicated that a strain of Synechococcus isolated from YNP was photosynthetically active at a temperature of $75^{\circ} \mathrm{C}$ (Allewalt et al., 2006), $2^{\circ} \mathrm{C}$ warmer than has been observed in YNP (Figure 2A). Although light-driven DIC uptake was observed in algal- and cyanobacterial-dominated phototrophic assemblages incubated at temperature locations that were $10^{\circ} \mathrm{C}$ higher $\left(56\right.$ and $78^{\circ} \mathrm{C}$, respectively), than the in situ temperature where the mats were sampled ( 46 and $68^{\circ} \mathrm{C}$, respectively), it only represented 3 and $2 \%$, respectively, of the activities observed at the in situ temperature. This finding is consistent with previous results indicating that photosynthesis in natural communities and isolates 
is most efficient at temperatures that correspond to those of the environment where the phototrophic assemblages were sampled, apparently due to evolutionary optimization to inhabit that particular ecological niche (Brock, 1967; Miller and Castenholz, 2000; Allewalt et al., 2006). To the extent that DIC uptake reflects the overall physiological state of the photosynthetic assemblages, these results indicate that temperature constrains the distribution of photosynthesis due to its effects on the physiology of the organisms comprising the community, thereby decreasing their overall fitness. As summarized by Cox et al. (2011) numerous hypotheses have been put forth regarding the mechanisms through which temperature may limit phototrophy, including arguments regarding protein stability (Kempner, 1963 ) and the functionality of the $\mathrm{CO}_{2}$-assimilating mechanism under thermal stress (Meeks and Castenholz, 1978). Biochemical experimentation that is beyond the scope of this study will be required to elucidate the molecules that are most sensitive to temperature stress and which are likely to restrict the diversification of phototrophs to environments with temperatures $>73^{\circ} \mathrm{C}$.

Although evidence is presented here to indicate that photosynthesis is possible at temperatures as high as $78^{\circ} \mathrm{C}$, it is unlikely that this activity is sufficient for reproductive success considering that photosynthesis has never been observed in nature above a temperature of $\sim 73^{\circ} \mathrm{C}($ Brock, 1967). In acidic environments $(\mathrm{pH}$ $<4-5$ ), the upper temperature limit for the distribution of photosynthetic metabolism is limited to locations with temperatures of less than $\sim 57^{\circ} \mathrm{C}$ (Lehr et al., 2007; Boyd et al., 2009b, 2010; Cox et al., 2011; Hamilton et al., 2011b). This is likely due to the transition from cyanobacterial-dominated phototrophic ecosystems to algal-dominated photosynthetic ecosystems over this $\mathrm{pH}$ interval (Brock, 1973; Hamilton et al., 2011b) coupled with the suppression of phototrophic activity in algae by hydrogen sulfide. As a result of degassing and oxidation (Langner et al., 2001; Cox et al., 2011), the elevated sulfide concentrations that are common in source fluids dissipate, ultimately reaching the concentrations of less than $\sim 5 \mu \mathrm{M}$ that enable algal phototrophs to grow and reproduce. Considering that numerous microorganisms have evolved to thrive at temperatures of $>73^{\circ} \mathrm{C}$ (Brock, 1985) and a number of cyanobacteria have evolved to tolerate up to $\mathrm{mM}$ concentrations of sulfide (Oren et al., 1979; Miller and Bebout, 2004), it is unclear why phototrophs have not radiated and expanded their habitat boundaries in YNP. Perhaps the edges of the habitat range reflect intrinsic limits of the photosynthetic apparatus itself. Such a scenario corresponds to a deep valley on a fitness landscape, whereby the sole mechanism to adapt to a higher temperature (high physiological stress) is through significant and rapid adaptation (Keymer et al., 2006). However, if trade-offs or costs associated with adaptation to higher temperatures result in a loss of fitness at the expense of the adaptive advantage for a thermotolerant photosynthetic apparatus, the organism will not persist and diversification will collapse back to the ancestral state. Additional physiological studies, employing an evolutionary framework such as that used by Miller and colleagues (Miller and Castenholz, 2000; Miller, 2003), will be required to elucidate the physiological parameter(s) underlying the upper temperature limit for photosynthesis.
Generalized additive models that comprise multiple explanatory variables were significant predictors of the distribution of phototrophic metabolisms in YNP, indicating additive interactions among variables that constrain their habitat range. However, it is not known if the additive interactions that lead to distributional patterns reflect additive constraints on the fitness of populations that comprise the habitat edge communities. Additional studies using ecologically representative isolates will facilitate the examination of the effect of co-variation among target parameters under controlled conditions on the activities and fitness of phototrophic populations. Importantly, a GAM that comprised variation in temperature, sulfide, and $\mathrm{pH}$ was only capable of explaining $67 \%$ of the variation in the distribution of photosynthetic metabolisms, indicating that $33 \%$ of the variation is due to other unaccounted for variables. Elevated concentrations of metals are common in YNP geothermal environments including copper, mercury, and zinc (McCleskey et al., 2005; King et al., 2006; Boyd et al., 2009a; Wang et al., 2011b). Such metals have been shown to inhibit the activity of photosynthetic organisms, primarily through their disruption of the light harvesting apparatus (Clijsters and van Assche, 1985; Küpper et al., 2002). The speciation and bioavailability of many metals, including mercury (Barkay et al., 2010; Wang et al., 2011b), vary with the composition and $\mathrm{pH}$ of the environment. Thus, the influence of $\mathrm{pH}$ on defining the habitat range of photosynthetic metabolism as identified by GAMs may relate to the bioavailability and speciation of the numerous metals that co-vary with $\mathrm{pH}$ and result in a decrease in the fitness of phototrophic organisms in YNP. It has also been suggested that the availability of DIC, which tends to be lower at high temperature(Weyl, 1959) and which tends to speciate toward carbonic acid at low pH (Amend and Shock, 2001), may place additional constraints on the activity and fitness of phototrophs(Hamilton et al., 2011b). Without sufficient inorganic carbon to serve as the oxidizing agent, photoautotrophs can become severely photoinhibited, leading to oxidative stress (Murata et al., 2007) which would decrease fitness and would presumably place an additional constraint on their distribution. Indeed, the availability of DIC was inversely correlated with $\mathrm{pH}$ in the sites examined in the present study. A future goal of this work is to integrate measurements of phototroph in situ activity, phototroph abundance data, phylogenetic data, and more detailed geochemical data (e.g., DIC, trace metals, etc.) such that a comprehensive fitness landscape can be developed for photosynthesis in YNP in order to effectively predict the constraints on the evolution of this key metabolic process in this early Earth analog environment.

\section{ACKNOWLEDGMENTS}

This work was supported by National Science Foundation grants 1123689 to Eric S. Boyd, 1123649 to Everett L. Shock, and PIRE0968421 to Eric S. Boyd and John W. Peters. Eric S. Boyd also acknowledges support from the NASA Astrobiology Institute (NAI) postdoctoral fellowship program for a portion of this work. The Astrobiology Biogeocatalysis Research Center at Montana State University was supported by a grant from the NAI (NNA08CN85A) to Eric S. Boyd and John W. Peters. Eric S. Boyd would like to thank Tom "Elmo" Werner for logistical support during the completion of this project. 


\section{REFERENCES}

Allewalt, J. P., Bateson, M. M., Revsbech, N. P., Slack, K., and Ward, D. M. (2006). Effect of temperature and light on growth of and photosynthesis by Synechococcus isolates typical of those predominating in the Octopus Spring microbial mat community of Yellowstone National Park. Appl. Environ. Microbiol. 72, 544-550.

Amend, J. P., and Shock, E. L. (2001). Energetics of overall metabolic reactions of thermophilic and hyperthermophilic archaea and bacteria. FEMS Microbiol. Rev. 25, 175-243.

Anbar, A. D. (2008). Elements and evolution. Science 322, 1481-1483.

Anbar, A. D., Duan, Y., Lyons, T. W., Arnold, G. L., Kendall, B., Creaser, R. A., Kaufman, A. J., Gordon, G. W., Scott, C., Garvin, J., and Buick, R. (2007). A whiff of oxygen before the great oxidation event? Science 317, 1903-1906.

Barkay, T., Kritee, K., Boyd, E., and Geesey, G. (2010). A thermophilic bacterial origin and subsequent constraints by redox, light and salinity on the evolution of the microbial mercuric reductase. Environ. Microbiol. 12, 2904-2917.

Blankenship, R. E. (1992). Origin and early evolution of photosynthesis. Photosyn. Res. 33, 91-111.

Blankenship, R. E. (2010). Early evolution of photosynthesis. Plant Physiol. 154, 434-438.

Boyd, E. S., Anbar, A. D., Miller, S., Hamilton, T. L., Lavin, M., and Peters, J. W. (2011). A late methanogen origin for molybdenum-dependent nitrogenase. Geobiology 9, 221-232.

Boyd, E. S., Hamilton, T. L., Spear, J. R., Lavin, M., and Peters, J. W. (2010). [FeFe]-hydrogenase in Yellowstone National Park: evidence for dispersal limitation and phylogenetic niche conservatism. ISME J. 4, 1485-1495.

Boyd, E. S., King, S., Tomberlin, J. K., Nordstrom, D. K., Krabbenhoft, D. P., Barkay, T., and Geesey, G. G. (2009a). Methylmercury enters an aquatic food web through acidophilic microbial mats in Yellowstone National Park, Wyoming. Environ. Microbiol. 11, 950-959.

Boyd, E. S., Leavitt, W. D., and Geesey, G. G. (2009b). $\mathrm{CO}_{2}$ uptake and fixation by a thermoacidophilic microbial community attached to precipitated sulfur in a geothermal spring. Appl. Environ. Microbiol. 75, 4289-4296.

Brock, T. D. (1967). Micro-organisms adapted to high temperatures. Nature 214, 882-885.
Brock, T. D. (1973). Lower pH limit for the existence of blue-green algae: evolutionary and ecological implications. Science 179, 480-483.

Brock, T. D. (1985). Life at high temperatures. Science 230, 132-138.

Buick, R. (2008). When did oxygenic photosynthesis evolve? Philos. Trans. R. Soc. Lond. B Biol. Sci. 363, 2731-2743.

Castenholz, R. W. (1977). The effect of sulfide on the blue-green algae of hot springs II. Yellowstone National Park. Microb. Ecol. 3, 79-105.

Chew, A. G. M., and Bryant, D. A. (2007). Chlorophyll biosynthesis in bacteria: the origins of structural and functional diversity. Annu. Rev. Microbiol. 61, 113-129.

Clijsters, H., and van Assche, F. (1985). Inhibition of photosynthesis by heavy metals. Photosyn. Res. 7, 31-40.

Cox, A., Shock, E. L., and Havig, J. R. (2011). The transition to microbial photosynthesis in hot spring ecosystems. Chem. Geol. 280, 344-351.

D’Imperio, S., Lehr, C. R., Oduro, H., Druschel, G., Kühl, M., and McDermott, T. R. (2008). Relative importance of $\mathrm{H} 2$ and $\mathrm{H} 2 \mathrm{~S}$ as energy sources for primary production in geothermal springs. Appl. Environ. Microbiol. 74, 5802-5808.

Falkowski, P. G., and Isozaki, Y. (2008). The story of O2. Science 322, 540-542.

Ferris, M. J., Magnuson, T. S., Fagg, J. A., Thar, R., Kühl, M., Sheehan, K. B., and Henson, J. M. (2003). Microbially mediated sulphide production in a thermal, acidic algal mat community in Yellowstone National Park. Environ. Microbiol. 5, 954-960.

Ferris, M. J., Sheehan, K. B., Kühl, M., Cooksey, K., Wigglesworth-Cooksey, B., Harvey, R., and Henson, J. M. (2005). Algal species and light microenvironment in a low-pH, geothermal microbial mat community. Appl. Environ. Microbiol. 71, 7164-7171.

Guisan, A., Edwards, T. C. Jr., and Hastie, T. (2002). Generalized linear and generalized additive models in studies of species distributions: setting the scene. Ecol. Model. 157, 89-100.

Guisan, A., and Thuiller, W. (2005). Predicting species distribution: offering more than simple habitat models. Ecol. Lett. 8, 993-1009.

Hamilton, T. L., Boyd, E. S., and Peters, J. W. (2011a). Environmental constraints underpin the distribution and phylogenetic diversity of nifH in the Yellowstone geothermal complex. Microb. Ecol. 61, 860-870.
Hamilton, T. L., Vogl, K., Bryant, D. A., Boyd, E. S., and Peters, J. W. (2011b). Environmental constraints defining the distribution, composition, and evolution of chlorophototrophs in thermal features of Yellowstone National Park. Geobiology 10, 236-249.

Hastie, R., and Tibshirini, R. (1986). Generalized additive models. Stat. Sci. 1, 297-318.

Hoehler, T. M. (2007). An energy balance concept for habitability. Astrobiology 7, 824-838.

Howsley, R., and Pearson, H. W. (1979). pH dependent sulfide toxicity to oxygenic photosynthesis in cyanobacteria. FEMS Microbiol. Rev. 6, 287-292.

Jackson, C. R., Langner, H. W., Donahoe-Christiansen, J., Inskeep, W. P., and McDermott, T. R. (2001). Molecular analysis of microbial community structure in an arseniteoxidizing acidic thermal spring. Environ. Microbiol. 3, 532-542.

Johnson, J. B., and Omland, K. S. (2004). Model selection in ecology and evolution. Trends Ecol. Evol. 19, 101-108.

Keddy, P. A. (1992). Assembly and response rules: two goals for predictive community ecology. J. Veg. Sci. 3, 157-164.

Kempner, E. S. (1963). Upper temperature limit of life. Science 142, 1318-1319.

Keymer, J. E., Galajda, P., Muldoon, C., Park, S., and Austin, R. H. (2006). Bacterial metapopulations in nanofabricated landscapes. Proc. Natl. Acad. Sci. 103, 17290-17295.

King, S. A., Behnke, S., Slack, K., Krabbenhoft, D. P., Nordstrom, D. K., Burr, M. D., and Striegl, R. G. (2006). Mercury in water and biomass of microbial communities in hot springs of Yellowstone National Park, USA. Appl. Geochem. 21, 1868-1879.

Küpper, H., Šetlík, I., Spiller, M., Küpper, F. C., and Prášil, O. J. (2002). Heavy metal-induced inhibition of photosynthesis: targets of in vivo heavy metal chlorophyll formation. J. Phycol. 38, 429-441.

Langner, H. W., Jackson, C. R., McDermott, T. R., and Inskeep, W. P. (2001). Rapid oxidation of arsenite in a hot spring ecosystem, Yellowstone National Park. Environ. Sci. Technol. 35, 3302-3309.

Lavorel, S., and Garnier, E. (2002). Predicting changes in community composition and ecosystem functioning from plant traits: revisiting the Holy Grail. Funct. Ecol. 16, 545-556.
Lehr, C. R., Frank, S. D., Norris, T. B., D'Imperio, S., Kalinin, A. V., Toplin, J. A., Castenholz, R. W., and McDermott, T. R. (2007). Cyanidia (Cyanidiales) population diversity and dynamics in an acidsulfate-chloride spring in Yellowstone National Park. J. Phycol. 43, 3-14.

Lizotte, M. P., Sharp, T. R., and Priscu, J. C. (1996). Phytoplankton dynamics in the stratified water column of Lake Bonney, Antarctica: I. Biomass and productivity during the winter-spring transition. Polar Biol. 16, 155-162.

McCleskey, R. B., Ball, J. W., Nordstrom, D. K., Holloway, J. M., and Taylor, H. E. (2005). Water-Chemistry Data for Selected Hot Springs, Geysers, and Streams in Yellowstone National Park, Wyoming, 2001-2002. Boulder, CO: U.S. Geological Survey.

Meeks, J. C., and Castenholz, R. W. (1978). Photosynthetic properties of the extreme thermophile Synechococcus lividus. II. Stoichiometry between oxygen evolution and $\mathrm{CO}_{2}$ assimilation. J. Therm. Biol. 3, 19-24.

Miller, S. R. (2003). Evidence for the adaptive evolution of the carbon fixation gene $\mathrm{rbcL}$ during diversification in temperature tolerance of a clade of hot spring cyanobacteria. Mol. Ecol. 12, 1237-1246.

Miller, S. R., and Bebout, B. M. (2004). Variation in sulfide tolerance of photosystem II in phylogenetically diverse cyanobacteria from sulfidic habitats. Appl. Environ. Microbiol. 70, 736-744.

Miller, S. R., and Castenholz, R. W. (2000). Evolution of thermotolerance in hot spring cyanobacteria of the genus Synechococcus. Appl. Environ. Microbiol. 66, 4222-4229.

Miller, S. R., Williams, C., Strong, A. L., and Carvey, D. (2009). Ecological specialization in a spatially structured population of the thermophilic cyanobacterium Mastigocladus laminosus. Appl. Environ. Microbiol. 75, 729-734.

Murata, N., Takahashi, S., Nishiyama, Y., and Allakhverdiev, S. I. (2007). Photoinhibition of photosystem II under environmental stress. Biochim. Biophys. Acta 1767, 414-421.

Nordstrom, D. K., Ball, J. W., and McClesky, R. B. (2005). "Ground water to surface water: chemistry of thermal outflows in Yellowstone National Park," in Geothermal Biology and Geochemistry in Yellowstone National Park, eds W. P. Inskeep and T. R. McDermott (Bozeman: Montana State University), 143-162. 
Oren, A., Padan, D., and Malkin, S. (1979). Sulfide inhibition of photosystem II in cyanobacteria (bluegreen algae) and tobacco chloroplasts. Biochim. Biophys. Acta 546, 270-279.

Raymond, J., and Segrè, D. (2006). The effect of oxygen on biochemical networks and the evolution of complex life. Science 311, 1764-1767.

Sessions, A. L., Doughty, D. M., Welander, P. V., Summons, R. E., and Newman, D. K. (2009). The continuing puzzle of the Great Oxidation Event. Curr. Biol. 19, R567-R574.

Shock, E. L., Holland, M., MeyerDombard, D., Amend, J. P., Osburn, G. R., and Fischer, T. P. (2010). Quantifying inorganic sources of geochemical energy in hydrothermal ecosystems, Yellowstone National Park, USA. Geochim. Cosmochim. Acta 74, 4005-4043.

Shock, E. L., and Holland, M. E. (2007). Quantitative habitability. Astrobiology 7, 839-851.
Wang, M., Jiang, Y.-Y., Kim, K. M., Qu, G., Ji, H.-F., Mittenthal, J. E., Zhang, H.-Y., and Caetano-Anollés, G. (2011a). A universal molecular clock of protein folds and its power in tracing the early history of aerobic metabolism and planet oxygenation. Mol. Biol. Evol. 28, 567-582.

Wang, Y., Boyd, E., Crane, S., LuIrving, P., Krabbenhoft, D., King, S., Dighton, J., Geesey, G., and Barkay, T. (2011b). Environmental conditions constrain the distribution and diversity of archaeal merA in Yellowstone National Park, Wyoming, U.S.A. Microb. Ecol. 62, 739-752.

Westoby, M. (2006). Phylogenetic ecology at world scale, a new fusion between ecology and evolution. Ecology 87, S163-S165.

Weyl, P. K. (1959). The change in solubility of calcium carbonate with temperature and carbon dioxide content. Geochim. Cosmochim. Acta 17, 214-225.
Wiens, J. J. (2004). Speciation and ecology revisited: phylogenetic niche conservatism and the origin of species. Evolution 58, 193-197.

Wiens, J. J., and Graham, C. H. (2005). Niche conservatism: integrating evolution, ecology, and conservation biology. Annu. Rev. Ecol. Evol. Syst. 36, 519-539.

Wood, S. N. (2004). Stable and efficient multiple smoothing parameter estimation for generalized additive models. J. Am. Stat. Assoc. 99, 673-686.

Wood, S. N. (2011). Fast stable restricted maximum likelihood and marginal likelihood estimation of semiparametric generalized linear models. $J$. R. Stat. Soc. B 73, 3-36.

Yee, T. W., and Mitchell, N. D. (1991). Generalized additive models in plant ecology. J. Veg. Sci. 2, 587-602.

Conflict of Interest Statement: The authors declare that the research was conducted in the absence of any commercial or financial relationships that could be construed as a potential conflict of interest.

Received: 05 December 2011; accepted: 30 May 2012; published online: 18 June 2012.

Citation: Boyd ES, Fecteau KM, Havig JR, Shock EL and Peters JW (2012) Modeling the habitat range of phototrophs in Yellowstone National Park: toward the development of a comprehensive fitness landscape. Front. Microbio. 3:221. doi: 10.3389/fmicb.2012.00221

This article was submitted to Frontiers in Microbiological Chemistry, a specialty of Frontiers in Microbiology.

Copyright (C) 2012 Boyd, Fecteau, Havig, Shock and Peters. This is an open-access article distributed under the terms of the Creative Commons Attribution Non Commercial License, which permits noncommercial use, distribution, and reproduction in other forums, provided the original authors and source are credited. 